\title{
Leveling of Superfilled Damascene Cu Film Using Two-Step Electrodeposition
}

\author{
Soo-Kil Kim, ${ }^{\text {a,* }}$ Soonsik Hwang, Sung Ki Cho, ${ }^{*}$ and Jae Jeong Kim**,z \\ Research Center for Energy Conversion and Storage, School of Chemical Engineering, \\ Seoul National University, Seoul 151-742, Korea
}

\begin{abstract}
To enhance the compatibility of electrodeposition with the chemical mechanical polishing process, we attempted to prevent step formation on active areas. In the absence of benzotriazole (BTA), the step heights increased with the decrease in the pattern width and the increase in the pattern density due to the locally condensed accelerator. However, the addition of BTA significantly suppressed the deposition kinetic through the deactivation of the accelerator. The two-step electrodeposition with modulated accelerator and BTA concentrations was found to be effective in the retardation of bump formation and the prevention of bumps from growing without an impact on the superfilling.
\end{abstract}

(C) 2005 The Electrochemical Society. [DOI: 10.1149/1.2139976] All rights reserved.

Manuscript submitted August 12, 2005; revised manuscript received September 16, 2005.

Available electronically December 6, 2005.

The bottom-up electrodeposition of $\mathrm{Cu}$ in the damascene structure can be attributed to the accumulation of an accelerator, such as 3-mercapto-1-propane sulfonic acid, sodium salt (MPSA) and bis(3-sulfopropyl)disulfide (SPS), which involved competitive adsorption $^{1-6}$ and redox reactions inside the trench. ${ }^{7-10}$ The accumulation of the accelerator inside the pattern brought about a locally higher concentration even after the complete filling of the pattern, which caused the topographic reversal (formation of bumps) and step formation at the densely patterned area. The step height generated by overdeposition at the active area had a strong relation to the dimension and the density of the patterns. ${ }^{11,12}$ The overdeposits on the densely patterned active area induced a reduced chemical mechanical polishing (CMP) throughput ${ }^{13}$ and caused problems such as erosion and dishing in the subsequent CMP process. Consequently, attempts to prevent the step formation during the electrodeposition, i.e., leveling using an organic leveler or electrochemical methods, have become one of the main issues in $\mathrm{Cu}$ electrodeposition. ${ }^{14,15}$

If it could be shown that the step formation originates with the local accumulation of the accelerator at a continuously and densely patterned active area, the deactivation of the accelerator after the complete filling of the patterns should be brought into focus as a leveling method. The deactivation of the accelerator can be attained through two methods. One is the electrochemical decomposition or desorption of the accelerator from the surface of the active area, and the other is organic leveling using a leveler that has both a superior adsorption capability to the accelerator on the $\mathrm{Cu}$ surface and a suppressing effect strong enough to disturb the accelerator. For electrochemical leveling, the instability of SPS near an open-circuit potential was reported. ${ }^{16,17}$ Reid et al. ${ }^{13}$ also mentioned the idea of accelerator deactivation using a reverse current flowing after pattern filling. Moreover, Uzoh et al. ${ }^{18}$ reported that they reduced the overdeposition to less than $20 \mathrm{~nm}$ through the electrochemical control of the activity of the accelerator and leveler.

Organic leveling requires a more precise understanding of the reciprocal actions between additives, including chemical reaction, competitive adsorption, dimension-controlled diffusion, and the accumulation of additives. Reid et al. ${ }^{13}$ described the basic concepts of leveler action and their corresponding leveling methods. However, the selection and development of the pertinent levelers and of the electrodeposition process requires further investigation.

Benzotriazole (BTA) has been known as a corrosion inhibitor ${ }^{19,20}$ and a deposition suppressor of $\mathrm{Cu}{ }^{21}$ There is also an investigation about $\mathrm{Cu}$ filling using BTA as a hybrid-mode additive showing an

\footnotetext{
* Electrochemical Society Student Member.

** Electrochemical Society Active Member.

${ }^{\text {a }}$ Current address: Metallurgy Division, National Institute of Standards and Tech-

nology, Gaithersburg, MD, 20899, USA.

z E-mail: jjkimm@snu.ac.kr
}

accelerating effect at low concentrations and an inhibiting effect at high concentrations. ${ }^{22}$ Due to its strong adsorption ability on the $\mathrm{Cu}$ surface and strong suppressing effects on the electrodeposition kinetics, BTA is considered as a prime candidate for a leveler. However, interaction of BTA with an accelerator and manifestation of the suppressing effect even in the presence of accelerator has been little investigated. In this study, the two-step leveling of damascene $\mathrm{Cu}$ electrodeposition is suggested, with the use of BTA as a leveler and of the conventional superfilling additives of the polyethylene glycol (PEG)-Cl--SPS system.

\section{Experimental}

The damascene-pattered substrates used in the experiments had the structures of $60 \mathrm{~nm} \mathrm{Cu} / 7.5 \mathrm{~nm} \mathrm{Ta} / 7.5 \mathrm{~nm}$ TaN with a pattern depth of $320 \mathrm{~nm}$ and various aspect ratios $(A / R)$ from 2 (width 160 $\mathrm{nm}$ ) to 1 (width $320 \mathrm{~nm}$ ) as well as a spacing from 160 to $320 \mathrm{~nm}$. The organic additives for the superfilling of $\mathrm{Cu}$ were composed of 50 and $25 \mu \mathrm{M}$ SPS, $88 \mu \mathrm{M}$ PEG (Mw 3400), and $1 \mathrm{mM} \mathrm{NaCl}{ }^{8,23-26}$ Besides the superfilling additives, $0.4 \mathrm{mM}$ and $2 \mathrm{mM} \mathrm{1,2,3-BTA}$ were used as levelers. Electrodeposition was performed either in one step or in two steps according to the BTA addition step. The details of the step separation and the additive compositions are shown in Table I. Electrodeposition was carried out at $-250 \mathrm{mV}$ [vs saturated calomel electrode (SCE)] with base electrolytes composed of $1 \mathrm{M}$ $\mathrm{H}_{2} \mathrm{SO}_{4}, 0.25 \mathrm{M} \mathrm{CuSO}_{4} \cdot 5 \mathrm{H}_{2} \mathrm{O}$, and the corresponding additives. The equipment used in applying the potential was an EG\&G PAR 263 potentiostat, and a $\mathrm{Cu}$ bar was used as the anode. After electrodeposition, all the samples were rinsed with deionized (DI) water and were dried in an $\mathrm{N}_{2}$ stream. Cross sections of the samples were observed with field-emission-scanning electron microscopy (FESEM) (JEOL, JSM 6330F).

\section{Results and Discussion}

Figure 1a shows the cross-sectional FESEM images of the electrodeposited $\mathrm{Cu}$ with superfilling additives composed of PEG, $\mathrm{Cl}^{-}$, and SPS on a pattered substrate with a pattern width of $160 \mathrm{~nm}$ and a spacing of $190 \mathrm{~nm}$. The upper and lower values in each figure represent the deposition time and generated step height, respectively. After $40 \mathrm{~s}$ deposition, the patterns were completely filled and slight bumps with $100 \mathrm{~nm}$ in height became evident. Close bumps on the active area were connected to one another and led to overdeposition and step formation. As the deposition time increased up to $90 \mathrm{~s}$, the step height also increased to $220 \mathrm{~nm}$, exhibiting an increasing function of the deposition time due to the continuous working of concentrated SPS on the active area. The step grew as high as $\sim 400 \mathrm{~nm}$ at deposition time of $180 \mathrm{~s}$.

The overdeposition rate on the active area, the step height, had a strong relation to pattern density and size, as shown in Fig. 1b. The upper and lower values in each figure represent the pattern size/ 


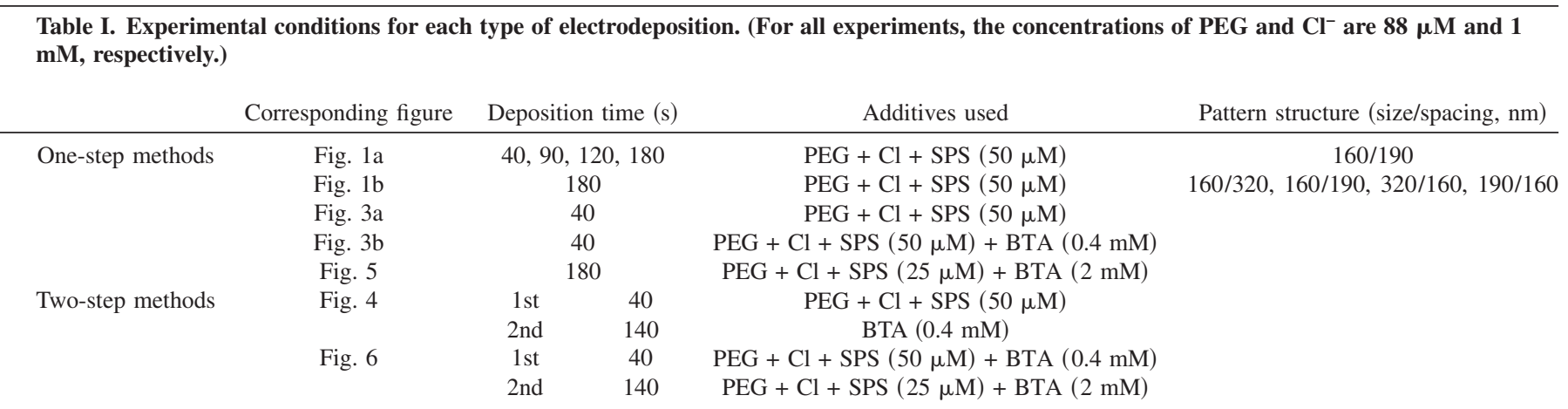

spacing and the generated step height after $180 \mathrm{~s}$ deposition, respectively. As clearly shown in the figure, the denser and the smaller the patterns were, the higher the step heights were, i.e., $394 \mathrm{~nm}$ at 190 $\mathrm{nm}$ spacing vs $370 \mathrm{~nm}$ at $320 \mathrm{~nm}$ spacing and $425 \mathrm{~nm}$ at $190 \mathrm{~nm}$ pattern size vs $278 \mathrm{~nm}$ at $320 \mathrm{~nm}$ pattern size, respectively. This implies that the pattern density and size had a strong correlation with the accumulation of the accelerator.

To prevent overdeposition and step formation, BTA was put in the electrolyte as an organic leveler. Prior to the leveling test, linear sweep voltammetry (LSV) was performed within the range of 50 to $-600 \mathrm{mV}$, with a scan rate of $20 \mathrm{mV} / \mathrm{s}$, to investigate the competitive adsorption between the additives, as proposed by Taephaisitphongse et al. ${ }^{27}$ The result is shown in Fig. 2a. A Cu rotating disk electrode with a rotation speed of $300 \mathrm{rpm}$ was used as a working electrode. The $I-V$ behaviors in the presence of no additive, PEG$\mathrm{Cl}^{-}$, and $\mathrm{PEG}-\mathrm{Cl}^{-}$-SPS were similar with those previously

(a) $40 \mathrm{~s}$


(b)

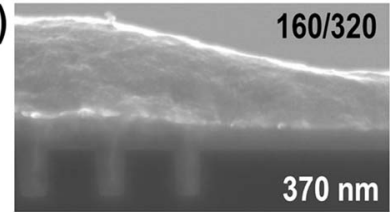

$370 \mathrm{~nm}$
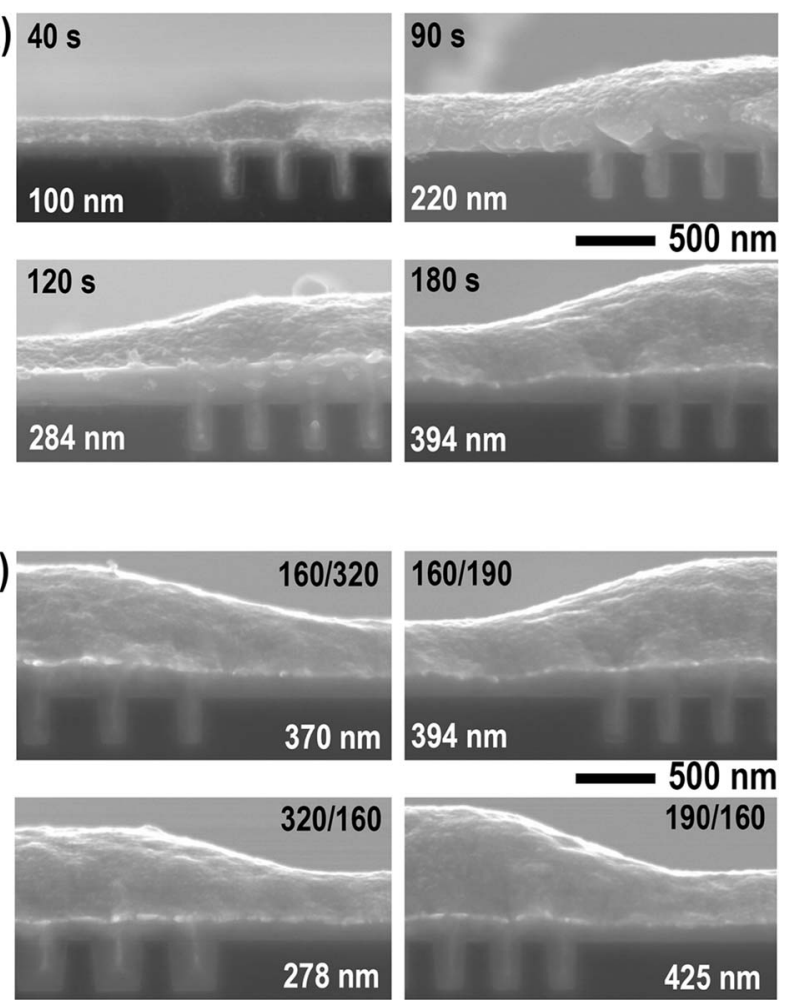

$160 / 190$

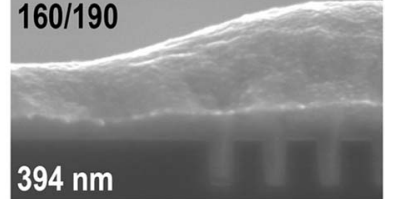

$500 \mathrm{~nm}$

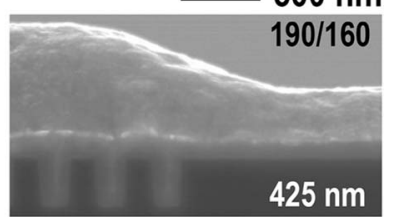

Figure 1. Cross-sectional FESEM images of the superfilled $\mathrm{Cu}$ on the PVD $\mathrm{Cu}$-seeded wafer (a) with a pattern width of $160 \mathrm{~nm}$ and a spacing of $190 \mathrm{~nm}$ for various deposition times and (b) with various pattern sizes and spacings for $180 \mathrm{~s}$. The additives used are composed of PEG, $\mathrm{Cl}^{-}$, and SPS. The lower values for each figure represent the generated step heights and the upper values correspond to the deposition time for (a) and pattern size (nm)/ spacing $(\mathrm{nm})$ for $(\mathrm{b})$, respectively. reported. ${ }^{16,27} \mathrm{PEG}^{-\mathrm{Cl}^{-}}$in the electrolyte significantly decreased the current density due to the adsorption on the $\mathrm{Cu}$ surface. However, the presence of SPS considerably recovered the current density, which was explained by the changes in the effective surface coverage of the PEG-based suppressor. ${ }^{27}$ Recently, attempts were made to attribute the increased deposition rate and the current density to the competitively adsorbed SPS from the viewpoint of the chemical reactions between the $\mathrm{Cu}$ ions and SPS or its reduced form (MPSA) ${ }^{7-10}$ There is a need to pay attention to the fact that the current density recovered by SPS re-decreased by BTA addition. The current density in the presence of BTA was even lower than that of PEG- $\mathrm{Cl}^{-}$within the potential range of 0 to $-400 \mathrm{mV}$. Considering that the suppressing effect is based on the adsorption of BTA, ${ }^{21}$ the
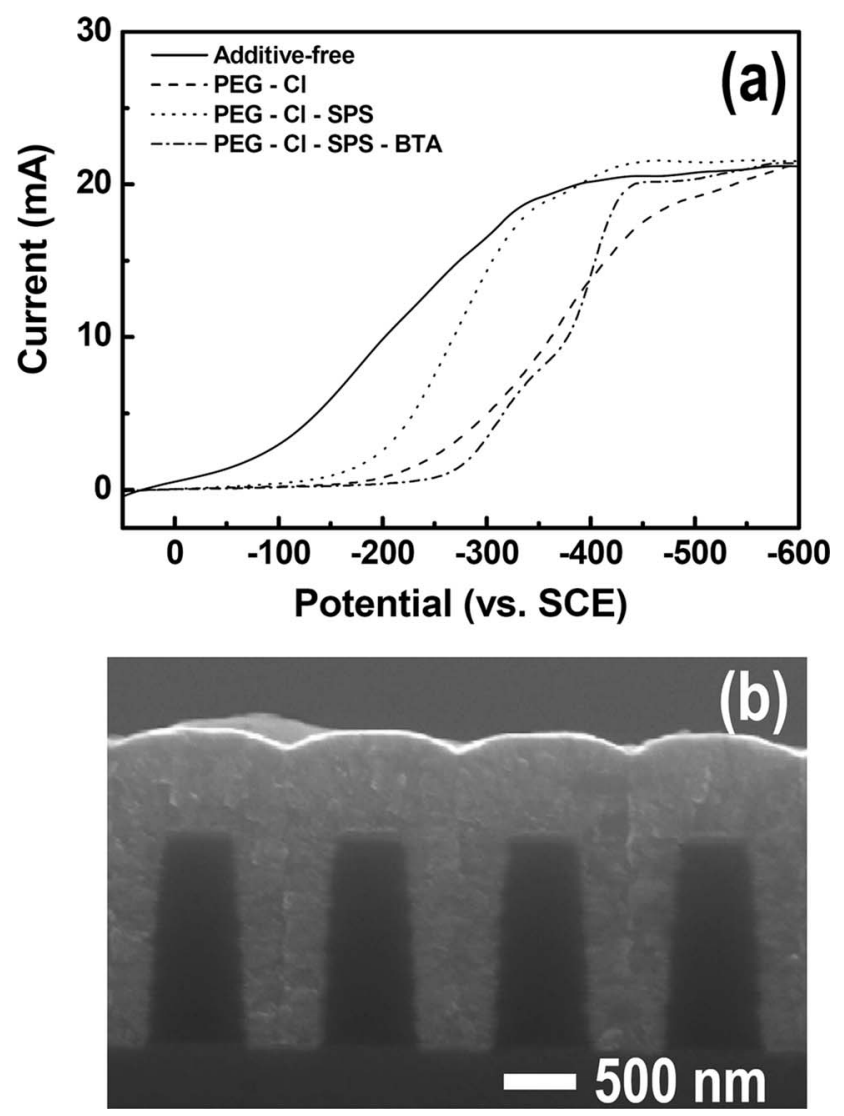

Figure 2. (a) LSV of $\mathrm{Cu}$ deposition in the presence of various organic additives. The scan range was from 50 to $-600 \mathrm{mV}$ with a scan rate of $20 \mathrm{mV} / \mathrm{s}$. A Cu rotating disk electrode with a rotation speed of $300 \mathrm{rpm}$ was used as the working electrode. (b) Cross-sectional FESEM image of the electrodeposited $\mathrm{Cu}$ for $400 \mathrm{~s}$ in the presence of BTA only. Large patterns were used for precise observation of the seam formation by added BTA. 
(a)
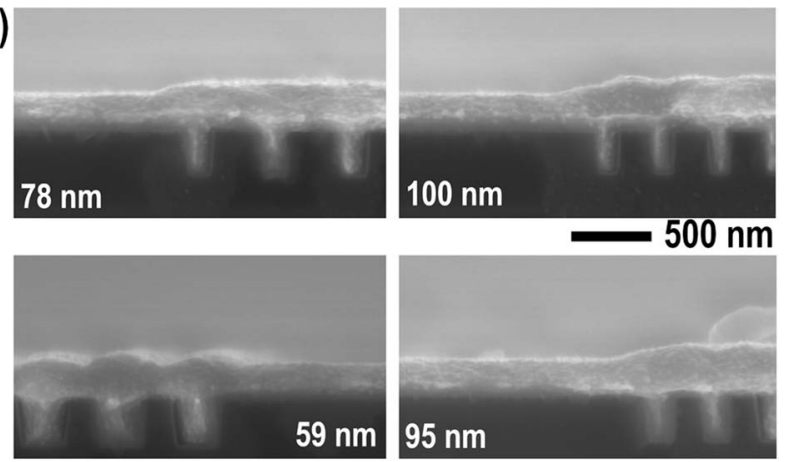

(b)
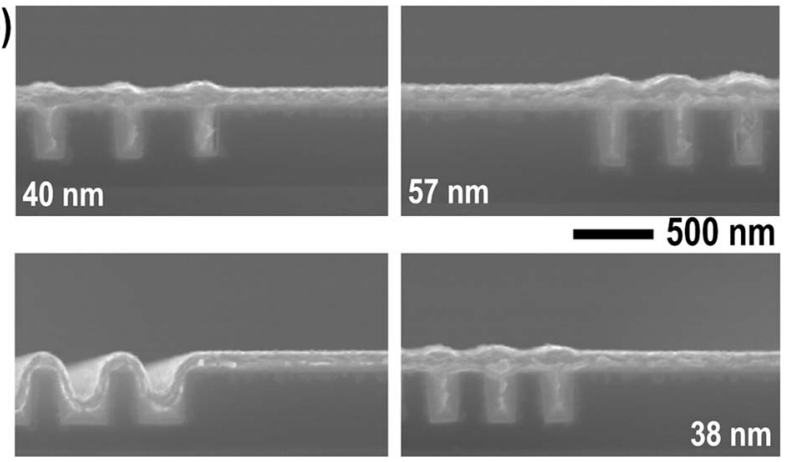

Figure 3. Cross-sectional FESEM images of (a) the superfilled $\mathrm{Cu}$ in the presence of PEG, $\mathrm{Cl}^{-}$, and SPS $(50 \mu \mathrm{M})$ for $40 \mathrm{~s}$ and (b) the superfilled $\mathrm{Cu}$ in the presence of PEG, $\mathrm{Cl}^{-}$, SPS $(50 \mu \mathrm{M})$, and BTA $(0.4 \mathrm{mM})$ for $40 \mathrm{~s}$, The upper values in (a) correspond to pattern size $(\mathrm{nm}) /$ spacing $(\mathrm{nm})$, which are also available for (b). The lower values for each figure represent the generated step heights.

LSV results implied that the BTA more strongly adsorbed on the $\mathrm{Cu}$ surface than SPS, which phenomena was limited to the flat surface where the surface concentration of the diffused additive was less restricted by the dimension of the additive than on a patterned surface. Since BTA has been known to form a large-sized polymeric structure through coupling with $\mathrm{Cu}$ ions and $\mathrm{Cu}$ surface, ${ }^{28,29}$ it can be expected that BTA may not have easy access to the trench inside due to its large size. Figure $2 \mathrm{~b}$ shows a cross-sectional image of the electrodeposited $\mathrm{Cu}$ in the presence of BTA alone. As expected, a conformal deposition with the seam at the center of the trench was obtained due to the concentrated BTA at the trench entrance and the gradually decreased amounts of diffused BTA along the trench depth. Therefore, when BTA was added to the electrolyte, the disturbance of the superfilling by BTA inside the trench, particularly in the patterns with small dimensions, was not serious.

To investigate the effect of the co-addition of BTA into the electrolyte, fill tests with BTA addition were performed. Figure 3a shows the FESEM images of the electrodeposited $\mathrm{Cu}$ with the PEG$\mathrm{Cl}^{-}$-SPS system for $40 \mathrm{~s}$. All kinds of patterns were completely filled and overdeposition, through the accumulation of SPS, and the connection of bumps were observed. Step heights followed the tendency shown in Fig. 1b, i.e., $100 \mathrm{~nm}$ at $190 \mathrm{~nm}$ spacing vs $78 \mathrm{~nm}$ at 320 $\mathrm{nm}$ spacing and $95 \mathrm{~nm}$ at $190 \mathrm{~nm}$ pattern size vs $59 \mathrm{~nm}$ at $320 \mathrm{~nm}$ pattern size, respectively. When BTA was added at the initial stage of the deposition, as shown in Fig. 3b, bumps were observed although they were not yet connected. A large pattern with $320 \mathrm{~nm}$ width remained unfilled but showed a bottom-up profile. These support the previous claim regarding the irrelevance of BTA to the radical action of SPS inside the pattern. However, the overall deposition thickness was reduced by the deposition-suppression effect of added BTA. The step heights were also reduced to half of those in Fig. 3a, i.e., 78 to $40 \mathrm{~nm}$ at 160/320 (line/spacing, nm) pattern, 100
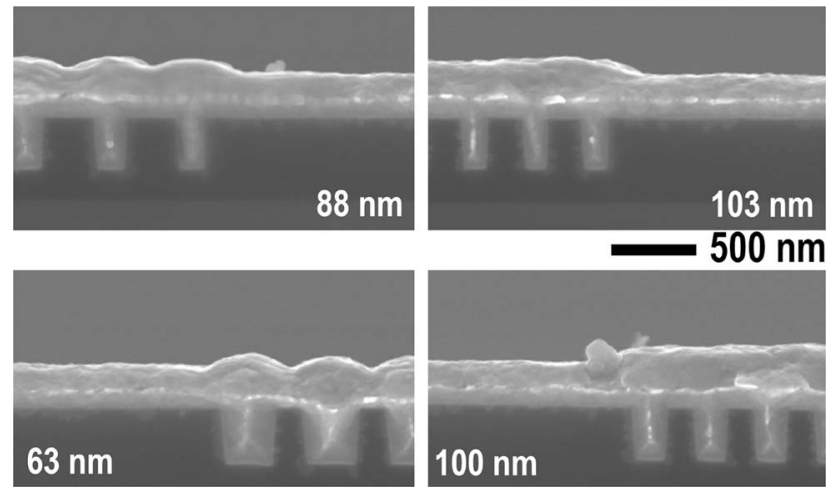

Figure 4. Cross-sectional FESEM images of the two-step filled $\mathrm{Cu}$ of which the first step was performed with PEG, $\mathrm{Cl}^{-}$, SPS $(50 \mu \mathrm{M})$ for $40 \mathrm{~s}$ and the second step with $0.4 \mathrm{mM}$ BTA alone for $140 \mathrm{~s}$. The pattern size $(\mathrm{nm}) / \mathrm{spacing}$ $(\mathrm{nm})$ are the same with those presented in Fig. 3a. The lower values for each figure represent the generated step heights.

to $57 \mathrm{~nm}$ at $160 / 190$ pattern, and 95 to $38 \mathrm{~nm}$ at $190 / 160$ pattern, respectively. This implies that BTA did not disturb the superfilling but could retard the bump formation. This is probably due to the small amounts of diffused BTA inside the trench, although they form a polymeric structure.

To investigate the effect of the second step addition of BTA, the samples in Fig. 3a, which had been electrodeposited with the PEG$\mathrm{Cl}^{-}$-SPS system for $40 \mathrm{~s}$, were further electroplated in the presence of BTA alone for $140 \mathrm{~s}$. The cross sections of the samples are shown in Fig. 4. Compared with the images in Fig. 3a the Cu film in Fig. 4 showed almost no growth even after another $140 \mathrm{~s}$ electrodeposition. It should be noted that the step height values in Fig. 4 are almost the same as those in Fig. 3a. This implies that the BTA that was added after the bump formation deactivated or displaced SPS which had been condensed on the bumps and showed a strong suppression effect leading to the prevention of further overdeposition. In fact, this method reduced the step height to one-quarter times the height generated from the electrodeposition with the PEG- $\mathrm{Cl}^{-}$-SPS system for the same $180 \mathrm{~s}$ deposition time, as can be seen when the second figure of Fig. 4 is compared with the fourth figure of Fig. 1a, which had the same pattern width and spacing.

Based on the results shown in Fig. 3 and 4, it can be said that with respect to the leveling, the electrodeposition process should be separated into the following two steps: $(i)$ the patterns should first be

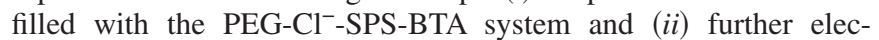
trodeposition should be performed with BTA alone. In this study, the following two-step processes were performed: the first step involved the PEG-Cl- ${ }^{-}$-SPS-BTA system, as proposed above, for $40 \mathrm{~s}$ when the small patterns were filled (see Fig. 3b); and the second step involved a reduced SPS concentration $(25 \mu \mathrm{M})$ and an increased BTA concentration $(2000 \mu \mathrm{M})$ to obtain the simultaneous effects of the filling of the unfilled large pattern and the leveling. For the modification of the concentration ratio, the patent of Jang, ${ }^{30}$ who used a commercial brightener and a leveler, is referred to. However, prior to adapting this two-step process, the effects of reduced SPS concentration $(25 \mu \mathrm{M})$ and increased BTA concentration $(2000 \mu \mathrm{M})$ on the deposition profile were characterized by applying this condition to fill the pattern through a one-step electrodeposition for $180 \mathrm{~s}$. The results are shown in Fig. 5. As is clearly shown in the figure, the deposited $\mathrm{Cu}$ with this condition revealed highly suppressed unfilled patterns even after $180 \mathrm{~s}$ deposition due to the reduced SPS concentration and increased BTA concentration. Even though the patterns remained unfilled, the shapes of the deposit presented the superfilling with the thicker film at the trench bottom than at the sidewalls. This implies that the electrodeposition with $25 \mu \mathrm{M}$ SPS and $2000 \mu \mathrm{M}$ BTA for $140 \mathrm{~s}$ can be successfully adapted as a second step to continue filling of the unfilled large patterns and to 

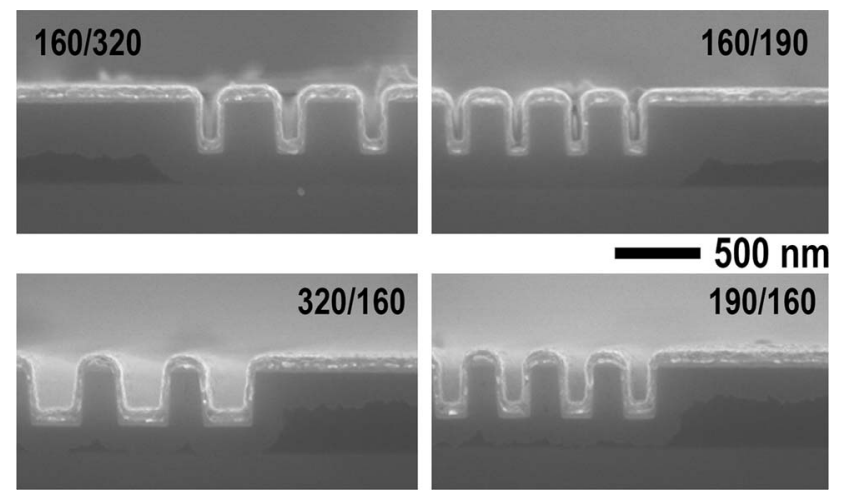

Figure 5. Cross-sectional FESEM images of the electrodeposited $\mathrm{Cu}$ in the presence of PEG, $\mathrm{Cl}^{-}$, SPS $(25 \mu \mathrm{M})$, and BTA $(2000 \mu \mathrm{M})$ for $180 \mathrm{~s}$. The upper values for each figure correspond to the pattern size $(\mathrm{nm}) / \mathrm{spacing}$ $(\mathrm{nm})$.

prevent the bumps on smaller patterns from growing further.

The results of the two-step fill test are shown in Fig. 6. As is clearly shown in the figures, a defect-free superfilling was observed in all the patterns, and a uniform film thickness without step formation was evident regardless of the pattern types. This indicates that the step formation was effectively prevented through the attenuation of bump formation by initially adding BTA and the inhibition of bump growth by the latter addition of increased amounts of BTA. It can therefore be said that BTA is a strong candidate for the leveling of the damascene electrodeposition of $\mathrm{Cu}$ with various pattern dimensions and densities.

\section{Conclusions}

The uneven deposition on the patterned active area due to the accumulated SPS was controlled by BTA which has a stronger ad-
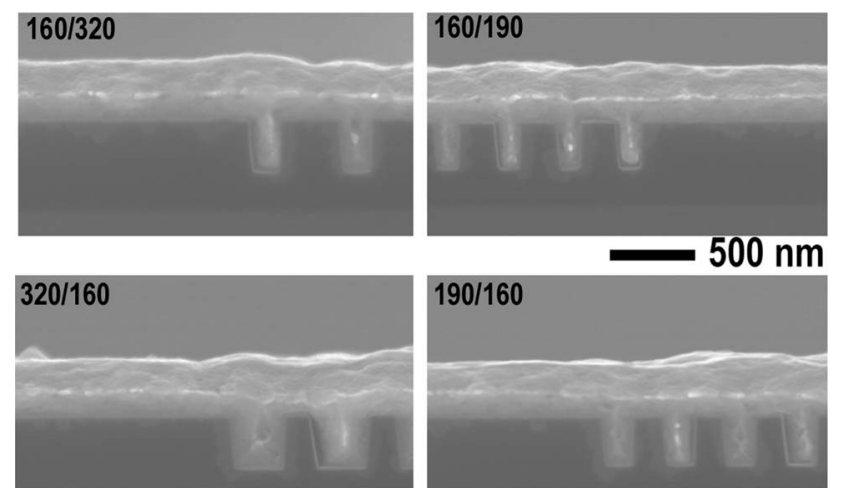

Figure 6. Cross-sectional FESEM images of the two-step electrodeposited $\mathrm{Cu}$; the first step in the presence of PEG, $\mathrm{Cl}^{-}$, SPS $(50 \mu \mathrm{M})$, and BTA $(0.4$ $\mathrm{mM}$ ) for $40 \mathrm{~s}$ and the second step in the presence of $\mathrm{PEG}, \mathrm{Cl}^{-}$, SPS $(25 \mu \mathrm{M})$, and BTA $(2 \mathrm{mM})$ for $140 \mathrm{~s}$. The upper values for each figure correspond to pattern size $(\mathrm{nm}) /$ spacing $(\mathrm{nm})$. sorption capability than SPS and subsequently deactivates SPS. BTA did not disturb the bottom-up filling because of its inaccessibility to the trench inside. Instead, BTA retarded the bump formation during its initial addition. The BTA that was added after bump formation prevented the bump from growing further. Therefore, it can be concluded that two-step leveling with modulated SPS and BTA concentrations is effective both in the superfilling of patterns with various dimensions and in their leveling.

\section{Acknowledgments}

This work was supported by the KOSEF through the Research Center for Energy Conversion and Storage and by the Institute of Chemical Processes.

Seoul National University assisted in meeting the publication costs of this article.

\section{References}

1. D. Josell, D. Wheeler, and T. P. Moffat, Electrochem. Solid-State Lett., 5, C49 (2002)

2. D. Josell, D. Wheeler, W. H. Huber, J. E. Bonevich, and T. P. Moffat, J. Electrochem. Soc., 148, C767 (2001).

3. D. Josell, D. Wheeler, W. H. Huber, and T. P. Moffat, Phys. Rev. Lett., 87, 016102 (2001).

4. T. P. Moffat, D. Wheeler, W. H. Huber, and D. Josell, Electrochem. Solid-State Lett., 4, C26 (2001).

5. D. Wheeler, D. Josell, and T. P. Moffat, J. Electrochem. Soc., 150, C302 (2003)

6. P. M. Vereecken, R. A. Binstead, H. Deligianni, and P. C. Andricacos, IBM J. Res. Dev., 49, 3 (2005).

7. J. J. Kim, S.-K. Kim, and Y. S. Kim, J. Electroanal. Chem., 542, 61 (2003).

8. S.-K. Kim and J. J. Kim, Electrochem. Solid-State Lett., 7, C98 (2004).

9. A. Frank and A. J. Bard, J. Electrochem. Soc., 150, C244 (2003).

10. T. P. Moffat, B. Baker, D. Wheeler, and D. Josell, Electrochem. Solid-State Lett., 6 C59 (2003).

11. P. Singer, Semicond. Int., 27(5) (2004).

12. Y. H. Im, M. O. Bloomfield, S. Sen, and T. S. Cale Electrochem. Solid-State Lett., 6. C42 (2003).

13. J. Reid, E. Webb, J. Sukamto, Y. Takada, and T. Archer, in Abstract 148, The Electrochemical Society Meeting Abstracts, Vol. 2004-1, San Antonio, TX, May 9-13, 2004.

14. M. X. Yang, D. Mao, C. Yu, J. Dukovic, and M. Xi, Solid State Technol., 46, 37 (2003).

15. S.-C. Chang, J.-M. Shieh, B.-T Dai, M.-S. Feng, Y.-H. Li, C. H. Shih, M. H. Tsai, S. L. Shue, R. S. Liang, and Y.-L. Wang, Electrochem. Solid-State Lett., 6, G72 (2003).

16. T. P. Moffat, D. Wheeler, and D. Josell, J. Electrochem. Soc., 151, C262 (2004).

17. J. P. Healy and D. P. Goodenough, J. Electroanal. Chem., 338, 167 (1992).

18. C. E. Uzoh, H. Talieh, T. Wang, and B. M. Basol, in Abstract 152, The Electrochemical Society Meeting Abstracts, Vol. 2004-1, San Antonio, TX, May 9-13, 2004.

19. G. K. Gomma, Mater. Chem. Phys., 5627 (1998).

20. J. R. Santos, Jr, L. H. C. Mattoso, and A. J. Motheo, Electrochim. Acta, 43309 (1998).

21. J. J. Kim, S.-K. Kim, and J.-U. Bae, Thin Solid Films, 415, 101 (2002).

22. K.-C. Lin, J.-M. Shieh, S.-C. Chang, B.-T. Dai, C.-F. Chen, M.-S. Feng, and Y.-H. Li, J. Vac. Sci. Technol. B, 20, 2233 (2002).

23. T. P. Moffat, J. E. Bonevich, W. H. Huber, A. Stanishevsky, D. R. Kelly, G. R. Stafford, and D. Josell, J. Electrochem. Soc., 147, 4524 (2000).

24. A. C. West, S. Mayer, and J. Reid, Electrochem. Solid-State Lett., 4, C50 (2001).

25. D. Josell, B. Baker, C. Witt, D. Wheeler, and T. P. Moffat, J. Electrochem. Soc., 149, C637 (2002).

26. T. P. Moffat, D. Wheeler, C. Witt, and D. Josell, Electrochem. Solid-State Lett., 5, C110 (2002).

27. P. Taephaisitphongse, Y. Cao, and A. C. West, J. Electrochem. Soc., 148 C492 (2001).

28. Y. Ling, Y. Guan, and K. N. Han, Corros. Sci., 51, 367 (1995).

29. R. Youda, H. Nishihara, and K. Aramaki, Corros. Sci., 28, 87 (1988).

30. S.-M. Jang, U.S. Pat. 6,350,364 (2002). 